\title{
A herança do PCH: balanço crítico e desdobramentos 40 anos depois
}

\begin{abstract}
Marcia Sant'Anna ${ }^{1}$
RESUMO: Este artigo realiza um balanço crítico do Programa de Cidades Históricas (PCH), implementado pelo governo federal do Brasil entre 1973 e 1987. O PCH constituiu a primeira política de preservação do patrimônio urbano de caráter amplo, integrado e descentralizado, sendo, até hoje, a que obteve os resultados mais duradouros, sejam positivos ou negativos. Neste trabalho - que se baseia em pesquisa realizada pela autora em meados dos anos 1990 e em pesquisas recentes feitas por outros autores - busca-se resgatar alguns aspectos pouco conhecidos do programa que são úteis para a reflexão atual sobre as políticas de preservação do patrimônio. Busca-se também avaliar, dos pontos de vista conceitual, institucional e operacional, a herança deixada por essa experiência que, de modo pioneiro, tentou executar a difícil tarefa de preservar o patrimônio urbano de modo economicamente sustentável - uma tarefa que ainda não foi executada de modo consistente e adequado no Brasil contemporâneo.

PALAVRAS-CHAVE: Política de preservação. Programa de Cidades Históricas. Patrimônio Urbano. Brasil.

ABSTRACT: The paper makes a critical assessment of the Historic Cities Program (HCP), implemented by the federal government of Brazil from 1973 to 1987. HCP was a first broad nature preservation policy, integrated and decentralized, and is until today, the one with the most durable results, whether positive or negative. This paper - based on research conducted by the author in the mid-1990s and in recent research by other authors -seeks to rescue some little-known aspects of this program that are useful to the current reflection on the heritage preservation policies. It also seeks to evaluate in a conceptual, institutional and operational point of view, the legacy of this experience that, in a pioneering way, attempted to perform the difficult task of preserving the urban heritage with economic sustainability - something still not achieved in contemporary Brazil in a consistent and satisfactory way.

KEYWORDS: Preservation Policy. Historic Cities Program. Urban Heritage. Brazil.
\end{abstract}

1. Professora Adjunta da Faculdade de Arquitetura da Universidade Federal da Bahia. E-mail: <santanna.m@gmail.com>. 
2. Ouro Preto, Mariana, São João del Rei, Tiradentes, Diamantina e Serro. Além dessas cidades, também um conjunto arquitetônico e urbanístico na cidade de Sabará, Minas Gerais.

3. Trechos de correspondência de Rodrigo Melo Franco de Andrade, primeiro presidente do atual Iphan, datada de 17/09/1941 e dirigida a Jair Brandão Costa, representante dessa instituição na recémtombada cidade de Diamantina. Fonte: Arquivo Central do Iphan - Seção Rio de Janeiro.

4. Segundo o Iphan, encontram-se hoje sob proteção do tombamento federal 77 conjuntos urbanos. Disponível em $<$ http://portal.iphan.gov.br/ pagina/detalhes/123>, acesso em 23 jun. 2015.

5. Adoto aqui o ano de 1987 como o de conclusão desse programa, baseada no trabalho de Sandra Rafaela Magalhães Corrêa (2012), $O$ Programa de Cidades Históricas (PCH): por uma política integrada de preservação do patrimônio cultural - 1973-1979.

6. Consubstanciado em diversos planos do governo militar como o Plano Estratégico d e Desenvolvimento - PED (1968), o I Plano Nacional de Desenvolvimento - PND (1972), o II PND (1975) e, dentro deste último, o Plano

$\mathrm{N}$ a c i o n a $1 \quad \mathrm{~d} \mathrm{e}$ Desenvolvimento Urbano.
Introdução

O Brasil foi um dos primeiros países do mundo a proteger áreas urbanas como patrimônio, não apenas como uma soma de monumentos históricos, mas enquanto fenômenos urbanos. Em 1938, logo após a criação do antigo Serviço do Patrimônio Histórico e Artístico Nacional, seis cidades de Minas Gerais ${ }^{2}$ tiveram seus núcleos urbanos tombados como "documentação viva da sua formação e desenvolvimento originários", o que the conferia uma "fisionomia peculiar" 3 . Apesar desse avanço conceitual e do expressivo número de sítios urbanos que, desde então, foram tombados ${ }^{4}$, jamais se conseguiu implantar e desenvolver no país uma política permanente de preservação desse universo patrimonial, que corresponde ainda a um vasto estoque imobiliário localizado, em grande parte, nas capitais e cidades mais importantes do país.

O Programa de Cidades Históricas (PCH), implementado pelo governo federal entre 1973 e 19875, foi a primeira tentativa de formulação e implementação de uma políitica dessa natureza e, examinando-se hoje os resultados alcançados por iniciativas posteriores como o Programa Monumenta e o atual Programa de Aceleração do Crescimento - Cidades Históricas (PAC-CH), é forçoso reconhecer que talvez tenha sido a mais abrangente e de resultados mais duradouros, positivos ou negativos.

O PCH surgiv e se desenvolveu como produto de uma confluência rara de mudança de paradigmas. De um lado, uma alteração significativa na orientação das políticas de preservação do patrimônio urbano no Brasil e, de outro, a retomada, em novas bases, do viés desenvolvimentista e integrado da políitica econômica e urbana do governo federal ${ }^{b}$, então voltada para a eliminação de desigualdades regionais, para a desconcentração produtiva e demográfica e para o fortalecimento da rede urbana. O turismo surgiu, à época, como o ponto ideal para unir o aproveitamento econômico do patrimônio urbano ao desenvolvimento regional. Ou seja, como a atividade produtiva mais adequada para retirar do pântano da deterioração física e da estagnação econômica algumas cidades e suas regiões.

O ponto forte do programa, ou seja, a possibilidade de estar na confluência de novas reflexões preservacionistas e macroeconômicas, foi também o que selou o seu fim. Como um programa dependente desse tipo de conjuntura, - PCH perdeu seu caráter de política estratégica, e se esvaziou, consideravelmente, na medida em que os resultados do desenvolvimentismo do governo militar foram revelando-se insuficientes e que a crise econômico financeira do final dos anos 1970 foi colocando o país de joelhos. Os saldos positivos ou negativos do programa, contudo, devem ser revisitados. Mais do que isso, devem ser objeto de reflexão por parte dos que formulam e implementam as atuais políticas de preservação, pois muito do que hoje surge como novidade, não é mais do que o novo modelo de uma roda que já foi inventada há muito tempo, foi utilizada e se quebrou. 
Este artigo tenta resgatar - com base em pesquisa realizada nos arquivos do PCH em Recife e em Brasília, em meados dos anos 1990, e também no resultado de pesquisas recentes ${ }^{7}$-, alguns de seus aspectos pouco conhecidos que são úteis para a reflexão atual. Busca também avaliar, dos pontos de vista conceitual, institucional e operacional, a herança deixada por essa experiência que, de modo pioneiro, tentou executar a difícil tarefa de preservar o patrimônio urbano de modo economicamente sustentável - uma tarefa que ainda não foi executada de modo consistente e adequado no Brasil contemporâneo.

Alguns antecedentes fundamentais

\section{A "virada" da política de preservação nos anos 1960}

Entre 1937 e 1967, devido a uma notável e rara continuidade administrativa sob a batuta de Rodrigo Melo Franco de Andrade 8 , o atual Instituto do Patrimônio Histórico e Artístico Nacional (lphan) consolidou-se como uma instituição eminentemente técnica e mais ou menos fechada ao mundo das negociações políticas. As mudanças ocorridas nas diretrizes que presidiam sua ação a partir dos anos 1960, não foram, portanto, resultado das grandes transformações políticas em curso naquela década; muito mais, um reflexo das transformações econômicas e urbanas ocorridas no país na década anterior.

novo surto de industrialização deflagrado nos anos 1950 impulsionou o crescimento econômico e a urbanização no Sudeste do Brasil e promoveu importantes transformações nas capitais e em cidades do interior da região, que foram contempladas com a instalação de indústrias e, assim, retiradas das longas letargias econômicas que propiciaram a sobrevivência do seu patrimônio cultural. A febre de instalação de indústrias, de crescimento populacional, de abertura de estradas, de modernização da infraestrutura e, por fim, as pressões de expansão urbana atingiram essas cidades históricas e defrontaram o Iphan com problemas urbanos que, rapidamente, colocaram em xeque o seu modo tradicional e pontual de gestão desse patrimônio. Ao lado disso, o modelo de crescimento industrial excessivamente concentrado no Sudeste, ampliou as correntes migratórias nessa direção e também o fosso de desigualdade entre essa e as demais regiões do país. Nestas últimas, o problema do Iphan eram, cada vez mais, a decadência e o arruinamento de um valioso patrimônio urbano, diante da falta de perspectiva econômica nessa vasta parte do território nacional ainda atrelada ao velho modelo agroexportador.

Foram esses dilemas e pressões, e não as crises políticas que culminaram no golpe militar de 1964, que moveram o Iphan no sentido de rever sua atuação e de buscar o apoio técnico internacional que forçou o redirecionamento de sua política de preservação. Já em 1964, e coincidindo com a abertura da
7. Refiro-me, principalmente, à pesquisa de Sandra Rafaela Magalhães Corrêa (2012).

8. Rodrigo M. F. Andrade aposentou-se em 1967, após 30 anos à frente da direção do Iphan. 
9. Ver Sandra Corrêa (2012, p. 81).

10. "Recomendação sobre a conservação dos bens culturais de ameaçados pela execução de obras públicas e privadas", aprovada pela $15^{a}$ Sessão da Conferência Geral da Unesco, em novembro de 1968

11. Ver Sandra Corrêa (2012, p. 82).

12. Diretor do Real Instituto de Estudo e Conservação do Patrimônio Artístico de Bruxelas.

13. Ver Ricardo dos Santos Teixeira (2014, p. 38-39).

14. Ver Sandra Corrêa (2012, p. 83).

15. Ver Michel Parent (1968). Esse documento está disponível no Arquivo Central do Iphan - Seção Rio de Janeiro, mas já foi traduzido e publicado em português, constando do livro organizado por Claudia Feirebend, denominado As missões da Unesco no Brasil: Michel Parent, de 2008.

16. Ver Ricardo dos Santos Teixeira (2014, p 41-43). representação da Unesco no Brasil, Rodrigo M. F. Andrade e Renato Soeiro arquiteto da casa que sucedeu o primeiro na direção do instituto - participavam de conferências realizadas por essa organização", nas quais se afinavam com as novas reflexões e propostas do campo preservacionista internacional e identificavam oportunidades de assistência técnica e captação de recursos.

Naquela época, como atestam documentos internacionais como as Normas de Quito (da Organização dos Estados Americanos, 1967) e a Recomendação de Paris (Unesco, 1968) 10, o turismo emergia como uma atividade capaz de promover a preservação e, ao mesmo tempo, o aproveitamento econômico do patrimônio, animando a implantação de programas como o Programa de Incremento do Turismo e de Recuperação de Recursos Naturais, da Unesco, um dos cogitados pelo Iphan, em 1966, como fonte para a obtenção de recursos ${ }^{1}$. De fato, a relação do Brasil com a Unesco (e com seu ideário) se estreitou nos anos 1960, o que pode ser verificado no relatório da missão de Paul Coremans a Ouro Preto'2, em 1964, no qual encaminha propostas para a conservação do conjunto, de fomento ao turismo e também de reestruturação do Iphan ${ }^{13}$. Mas foram as missões de apoio técnico de Michel Parent, então inspetor principal dos monumentos franceses, em 1966 e 1967, que impulsionaram, de modo mais definitivo, a transformação da postura e da política do Iphan relativas ao patrimônio das chamadas "cidades históricas".

Além de examinar a situação do patrimônio protegido, Parent veio ao Brasil com o objetivo de avaliar a demanda do instituto de se implementar aqui um Plano de Incentivo ao Turismo Cultural ${ }^{14}$. No relatório elaborado após suas duas visitas, o consultor francês identificou no país um potencial turístico importante e digno de interesse internacional, cujo desenvolvimento estaria condicionado, entretanto, a uma série de providências: planejamento urbano e controle dos impactos do turismo nas cidades históricas, repartição de competências entre as esferas de governo, gestão integrada desse patrimônio por parte do poder público, formação de quadros técnicos e reestruturação administrativa do Iphan, entre outras ${ }^{15}$. Um dos desdobramentos imediatos desse relatório foi a vinda do arquiteto e urbanista português Alfredo Evangelista Viana de Lima, sob os auspícios do Programa de Monumentos Históricos no Desenvolvimento do Turismo da Unesco, que elaborou, entre 1968 e 70, um plano de preservação para a cidade de Ouro Preto, no qual enfatizava, entre outras observações, a importância do patrimônio dessa cidade como o recurso capaz de deflagrar um novo ciclo econômico baseado no turismo cultural ${ }^{16}$.

As principais diretrizes que passariam a fundamentar a política de preservação do patrimônio conduzida pelo Iphan já estavam, assim, colocadas na mesa quando Renato Soeiro assumiu a direção da instituição em 1967. Era preciso, contudo, buscar recursos financeiros para sua implementação, o que ocorrerá somente com a criação do Programa de Cidades Históricas, em 1973. 
Contexto de criação e implementação do PCH

O Programa de Reconstrução das Cidades Históricas do Nordeste denominação inicial do PCH - foi criado, assim, num contexło de renovação administrativa do Iphan e de mudança do paradigma preservacionista que ressaltava os valores estéticos e contemplativos do patrimônio, em prol da ênfase no seu valor econômico e na sua importância como insumo do turismo. Para tanto, como já haviam apontado diversos consultores da Unesco, era preciso buscar novas formas de gestão, juntar esforços e dividir a tarefa da preservação com outros entes governamentais. Essas foram as ideias que Renato Soeiro levou ao então Ministro da Educação, Jarbas Passarinho, e que animaram a promoção dos célebres Encontros de Governadores, que ficaram conhecidos como Compromissos de Brasília (1970) e de Salvador (1971) - eventos que começaram a mudar a face da gestão do patrimônio no Brasil e inauguraram o crescente envolvimento da esfera estadual na preservação do patrimônio cultural.

Essas movimentações institucionais, contudo, dificilmente teriam dado frutos importantes sem que essas novas diretrizes encontrassem eco na política macroeconômica e urbana do governo militar. Cabe ressaltar, a ênfase que essa política dava à diminuição das desigualdades regionais do país pela via da desconcentração de atividades produtivas e da busca de novas vocações econômicas, o que permitiu o direcionamento de significativos investimentos para as regiões Norte e Nordeste. Outros traços importantes dessa política macroeconômica foram o envolvimento dos demais entes federados na execução de ações para o desenvolvimento ${ }^{17}$, e financiamento dos investimentos públicos por meio da importação de capital.

O I Plano Nacional de Desenvolvimento (I PND), implementado entre 1972 e 1974, além de conter diretrizes voltadas para a implantação de polos agroindustriais no Nordeste, ressaltava o turismo, interno e internacional, como atividade importante para o desenvolvimento dessa região e suas belezas paisagísticas, seu litoral e seu patrimônio histórico como importantes insumos. ○ II PND (1975-1979), por sua vez, apesar do foco na implementação de uma Política Nacional de Desenvolvimento Urbano (PNDU), manteve a diretriz de desenvolvimento do turismo no Nordeste, articulando-a ao que essa política classificava como Áreas ou Subsistemas de Dinamização e de Promoção ${ }^{18}$.

Além desses planos de desenvolvimento de caráter macroeconômico, o governo militar desenvolveu também os chamados "Programas Integrados" voltados para o desenvolvimento urbano e regional, com foco especial no Nordeste, que tinham como principal característica operar com recursos financeiros de várias áreas de governo, mas que, a partir de 1973, foram reunidos no Fundo de Desenvolvimento de Programas Integrados (FDPI). Esse conjunto de iniciativas, planos e programas, juntamente com o acesso fácil a dinheiro externo, permitiram que o regime militar estabilizasse a crise econômica e alimentasse, entre 1967 e 73, o surto de crescimento que ficou conhecido como o "milagre econômico"19.
17. O Plano de Ação Concentrada (PAC), que fazia parte do Plano Estratégico d e Desenvolvimento (PED), vigente entre 1968 e 1970 , visava a coordenação das instâncias federadas e incluía diretrizes de descentralização e fortalecimento municipal. Ver Sandra Corrêa (2012, p. 63).

18. Ver Sandra Corrêa, 2012, pp 56-62.

19. Ver Rubens Penha Cysne (1994, p. 236). 
20. Ver a respeito, Ruben George Oliven (1984, p. 5051)

21. Ver Sandra Corrêa (2012).

22. O programa foi criado a partir do encaminhamento da Exposição de Motivos $\mathrm{n}^{\circ}$ 076-B, de 21/05/73, à Presidência da República.
Apesar da crise do petróleo de 1974, que desacelerou a economia e forçou mudanças no modelo de desenvolvimento, o reajustamento econômico permaneceu ancorado na importação de capital. A desaceleração impactou a política urbana, que abandonou as intervenções rodoviaristas do período do "milagre" e passou a buscar alternativas que incluíam, entre outras, a preservação de recursos naturais e do patrimônio histórico como insumo econômico para metrópoles e cidades médias do Nordeste. No começo dos anos 1980, entretanto, a redução dos empréstimos externos, devido ao aumento das taxas de juros e a uma nova crise do petróleo, selou o fim da onda desenvolvimentista, a queda do regime militar e, com isso, o progressivo esvaziamento dos programas integrados.

O período militar também se caracterizou pelo papel desempenhado pelo Estado na área cultura ${ }^{20}$. A importância dada então à cultura como via de integração nacional e de promoção da unidade em torno de um projeto político e de poder equivale àquela do Estado Novo. Com isso, um importante conjunto de instituições foi criado para a implantação de uma política nacional de cultura abrangente, destacando-se o Conselho Federal de Cultura (1967), a Embrafilme (1969), a Fundação Nacional de Arte (Funarte) e o Centro Nacional de Referência Cultural (CNRC), ambos em 1975. O Programa de Cidades Históricas - PCH fez parte desse conjunto e, como se detalhará em seguida, se encaixou perfeitamente nas diretrizes macroeconômicas, de desenvolvimento urbano, de descentralização, de integração de agências governamentais e de apoia à cultura do governo militar. Por essa razão é que, como propõe Sandra Corrêa, ele pode ser definido como a primeira política integrada de preservação implementada no Brasi|21 .

O PCH como política integrada de preservação.

\section{Criação e características do programa}

João Paulo dos Reis Velloso, nordestino e ministro da Secretaria de Planejamento da Presidência da República (Seplan-PR), foi figura de proa da criação, em 1973, do então Programa Integrado de Reconstrução das Cidades Históricas do Nordeste ${ }^{22}$. Um grupo de trabalho interministerial, constituído por representantes dos antigos ministérios do Planejamento e Coordenação Geral e da Educação e Cultura, da Embratur e da Sudene, foi responsável por sua formulação e inserção na já comentada linha de programas integrados do governo federal, daí o papel central da Seplan-PR em sua coordenação. O foco das ações do programa eram os estados do Nordeste, dentro, portanto, das perspectivas de desenvolvimento da região. $\bigcirc$ objetivo era incrementar a atividade turística e promover a conservação do patrimônio por meio da ação integrada das esferas de governo e do investimento em obras de restauração de monumentos e de infraestrutura turística, em formação de mão de obra e de técnicos especializados, e em projetos, pesquisas e planos de desenvolvimento urbano. 
fato de o programa ser gerido pela Seplan-PR foi visto no Iphan como um sinal de esvaziamento da instituição e como um desvirtuamento da nova política de preservação construída com o apoio da Unesco. $\bigcirc$ desenvolvimento do programa, entretanto, cuidou de provar o erro dessa avaliação inicial, já que impulsionou a modernização e o reaparelhamento do lphan, bem como o aumento de sua presença no território nacional. A divisão de competências e a concessão de dotações orçamentárias específicas foram também dobrando as resistências da instituição.

Na fase nordestina, o PCH foi coordenado por Seplan-PR, Iphan, Embratur e Sudene, em consonância com a área de competência de cada uma dessas instituições. No plano estadual, o programa era executado por instituições ligadas à preservação do patrimônio, à cultura e/ou ao turismo, sendo a grande maioria das primeiras criada em função do programa ${ }^{23}$. Os recursos, provenientes do FDPI, eram repassados às entidades estaduais, por meio de convênios, após a aprovação das propostas pela coordenação nacional e da prestação de uma contrapartida de $20 \%$ por parte dos estados. A integração imediata do imóvel restaurado à atividade turística ou sua utilização como equipamento público constituíam as principais garantias de prioridade. Havia a intenção de inserir, progressivamente, o poder municipal nessa cadeia de apoio técnico e financeiro, mas isso não se viabilizou.

Ainda na fase Nordeste, o programa não investiu em projetos habitacionais ou voltados para a promoção de atividades comerciais. Em todo o período de 1973 a 1976, dentre os 54 projetos executados, a grande maioria relacionava-se à recuperação de edifícios para a instalação de equipamentos públicos ou turísticos, contabilizando-se apenas dois planos diretores para as cidades de São Cristóvão e Laranjeiras, em Sergipe, e uma intervenção urbanística no Largo da Prefeitura desta última cidade 24 . Os grandes avanços do período foram a inclusão dos estados da região no trabalho de preservação do patrimônio - até então, praticamente, uma tarefa exclusiva do lphan - e a inserção dessa atividade na esfera econômica por meio da participação da Embratur e da Sudene no programa. Outras conquistas importantes foram a estruturação de um setor empresarial voltado para a restauração e a conservação de edifícios históricos, a dinamização da construção civil em pequenas e médias cidades, bem como a valorização de artesãos, materiais e tecnologias tradicionais de construção.

Mas houve também muitos problemas. $\bigcirc$ principal deles foi a ausência de formulação de políticas estaduais de preservação que garantissem a articulação dos investimentos à realização dos principais resultados esperados do programa, ou seja: a promoção de investimentos privados nas cidades históricas, a conservação progressiva e sustentada do seu patrimônio edificado, e o incremento da atividade turística como alavanca do desenvolvimento local. Além disso, os governos estaduais não realizavam as obras de infraestrutura necessárias para colocar em marcha esse processo e, muitas vezes, não conseguiam aportar os recursos necessários à efetivação das contrapartidas, o que inviabilizou algumas
23. Antes do PCH existiam apenas os seguintes organismos estaduais: a antiga Fundação do Patrimônio Artístico e Cultural da Bahia, hoje instituto, o Conselho de Defesa do Patrimônio Histórico, Arqueológico, Artístico e Turístico Condephaat, de São Paulo, e o Instituto Estadual do Patrimônio Cultural Inepac, do Rio de Janeiro, todos criados nos anos 1960.

24. Ver Marcia Sant'Anna (2014, p. 223-224). 
25. A Exposição de Motivos $\mathrm{n}^{\circ}$ 320/79, de 08/11/79, oficializou essa mudança nos objetivos do PCH. ações. Assim, após três anos de execução, já se verificava que a conservação progressiva do patrimônio urbano nordestino não seria lograda com esse modelo de ação. A ausência de um esquema de financiamento para iniciativas particulares concorreu também para desestimular o setor privado, tornando ainda mais pesada a carga de investimentos públicos. O programa, contudo, foi avaliado positivamente e, em atendimento a pressões políiticas, foi ampliado, a partir de 1976, para os estados do Sudeste e, em 1979, para todo o território nacional.

O processo de expansão do $\mathrm{PCH}$ para os estados do Sudeste implicou mudanças nos rumos do programa e a homogeneização de suas normas, a exemplo da obrigatoriedade de que todos os estados participantes possuíssem legislação de proteção e de que os imóveis objeto de intervenção possuíssem, pelo menos, o status de bens tombados pelos respectivos governos estaduais. A coordenação nacional do programa foi acrescida do Conselho Nacional de Política Urbana (CNPU), permanecendo a Seplan-PR no seu controle até 1979. Essa fase correspondeu a uma importante inflexão na políitica de financiamento do PCH, com diminuição da ênfase no desenvolvimento do turismo, com a inclusão de projetos articulados à solução de problemas urbanos e com a priorização de áreas sob ameaça de estagnação econômica, crescimento urbano desordenado ou turismo predatório. Essas novas diretrizes correspondem ao resultado de um balanço crítico da fase nordestina do programa, o que $\mathrm{o}$ aproximou mais das diretrizes delineadas pelo Iphan nos anos 1960 com o apoio dos consultores da Unesco.

Apesar dessas correções de rumo, o desempenho executivo no Sudeste não foi tão bom quanto no Nordeste e a ampliação do programa para todo o território nacional, a partir de 1979 - coincidindo com a transferência de sua gestão para o Iphan -, correspondeu à perda de sua característica principal e mais importante: a de um programa integrado e estratégico do governo federal. Essa perda, que implicou uma perda de importância, decorreu, principalmente, da forte desaceleração da economia brasileira após o choque do petróleo de 1974 - e da consequente retração dos investimentos públicos -, ocasionando o esvaziamento do FDPI. A equipe econômica do governo de João Batista Figueiredo abandonou, definitivamente, o discurso desenvolvimentista e esvaziou os programas integrados do período anterior, argumentando-se, inclusive, que o fim de sua vigência estaria previsto com a conclusão do II PND, em 1979.

A perda do foco regional e a expansão da abrangência territorial do programa, num momento de fragilidade econômica, de diminuição dos recursos financeiros e de sua pulverização em obras de restauração e conservação relacionadas ao dia-a-dia do lphan, marcaram o início do processo de esvaziamento e esgotamento que levaram-no ao fim. Apesar disso, ainda que no nível do discurso, mudou-se a estratégia de atuação do $\mathrm{PCH}^{25}$, tornando-o não mais um programa de desenvolvimento regional, via turismo, mas um programa nacional com ações voltadas para a formulação de políticas estaduais e municipais de preservação; para o apoio à elaboração de planos urbanos para núcleos históricos; para o incentivo à adoção de legislações estaduais e municipais de proteção ao 
patrimônio; para a promoção de atividades culturais locais, formação de recursos humanos e incentivo à pesquisa sobre bens culturais. Na sua reta final, portanto, o PCH tornou-se, na realidade, uma espécie de rubrica orçamentária especial e principal fonte de recursos do recém-criado sistema federal que articulou a então Secretaria do Patrimônio Histórico e Artístico Nacional - SPHAN à Fundação Nacional Pró-Memória - FNPM26.

Mas tornar-se um programa do sistema SPHAN/FNPM, por si só, não explica a dificuldade enfrentada pelo $\mathrm{PCH}$ para se tornar uma política transformadora da situação de deterioração, estagnação e descaracterização de cidades e setores históricos, notadamente no Nordeste, bem como de se efetivar como uma política de preservação de caráter permanente, aliada ao desenvolvimento urbano. Além dos já mencionados problemas de execução, talvez - "calcanhar de Aquiles" do programa tenha sido sua atuação por meio de intervenções arquitetônicas pontuais e não mediante um conjunto de ações articuladas a planos de preservação dotados de dimensões normativas e propositivas, e a instrumentos eficientes de gestão, financiamento e monitoramento. Além disso, havia muita dependência de investimentos públicos e pouca promoção do investimento privado. Outro problema relacionava-se ao investimento excessivo em usos turísticos, culturais, institucionais e religiosos - 79\% dos projetos contemplados com recursos do programa correspondiam a essas destinações ${ }^{27}$-, em confronto com o baixo investimento em planejamento, infraestrutura urbana e em promoção do uso residencial, que correspondeu a apenas 1\% do total. A falta de intervenções na melhoria de acessos, em infraestrutura e saneamento urbano, divulgação interna e externa de destinos turísticos, promoção de voos em número suficiente e adequado, além da considerável distância do Brasil dos principais países emissores de turistas, tornaram as ações do programa, virtualmente, incapazes de alavancar o turismo e torná-lo uma âncora da dinamização das economias locais. $\bigcirc$ fato de apenas cerca de $20 \%$ dos imóveis restaurados pelo $\mathrm{PCH}$ terem se mantido conservados até os anos 1990 é um bom indicador desse problema estrutural28.

$\bigcirc \mathrm{PCH}$ promoveu, contudo, impactos importantes no quadro dos tombamentos federais durante seu período de vigência, assim como na prática de restauração e conservação do patrimônio edificado. Consoante os ditames da Carta de Veneza (1964) e as recomendações dos consultores da Unesco que vieram ao Brasil nos anos 1960, o programa desempenhou um papel importante no aumento significativo do número de sítios urbanos tombados no Nordeste ${ }^{29}$. exame dos processos de tombamento da época mostra que, ao lado do vínculo dos sítios urbanos com os ciclos econômicos que acompanharam a formação do país e da existência de uma homogeneidade arquitetônica e estilística, surgiram como predicados importantes, em função do programa, a presença de belezas naturais e o potencial turístico do lugar.

As principais operações de conservação e restauração do patrimônio edificado, entre os anos 1970 e começo da década de 1980, ocorreram também
26. A SPHAN, instituída pelo Decreto-lei $\mathrm{n}^{\circ} 84.198$, de $13 / 11 / 1979$, passou a atuar como o braço legal e dotado de poder de polícia de um sistema que contava com a FNPM, criada pela Lei $\mathrm{n}^{\circ}$ 6.757 , de 17/12/1979, como seu braço executivo.

27. Ver Marcia Sant'anna (2014, p. 368).

28. Ibid. (p. 234).

29. A Bahia, estado do Nordeste que mais teve projetos financiados pelo $\mathrm{PCH}$, concentrou a maior parte dos tombamentos em sítios urbanos. Foram então protegidos as seguintes cidades e centros históricos: Porto Seguro (ampliação), Cachoeira, Lençóis, Rio de Contas, Itaparica e Mucugê. 
30. Cerca de 73,9 milhões de dólares, entre 1973 e 1983 , incluindo contrapartidas dos estados. Ibid. (p. 369).

31. Laranjeiras e São Cristóvão, em Sergipe; Marechal Deodoro, em Alagoas; o Plano Geral de Recuperação do Pelourinho, em Salvador; Barão de Cocais, Catas Altas, Conceição do Mato Dentro, Diamantina, Prados, Santa Bárbara, Santa Rita Durão, São João del Rei, Serro e Tiradentes, em Minas Gerais. Ver Marcia Sant'anna (2014, p. 249-252).

32. Sobre a primeira fase do Programa Monumenta, ver Marcia Sant'anna (2004). Para um balanço geral desse programa, ver Nabil Bonduki (2010).

33. Além da sede na cidade do Rio de Janeiro, o Iphan atuava por meio de representações: em São Paulo, para cuidar do patrimônio desse estado e dos demais estados da região Sul; em Minas Gerais; em Pernambuco, para atuar em todos os estados do Norte e do Nordeste acima de Sergipe; e na Bahia, que cuidava desse estado e também de Sergipe.

34. Foram criadas uma representação regional para o Centro-Oeste, com sede em Brasília; uma para a região Norte, com sede no Pará; uma para o Sul, com sede em Porto Alegre; e mais uma no Nordeste, abrangendo, os estados do Maranhão, Piauí e Ceará. no âmbito do $\mathrm{PCH}$, então a principal fonte de financiamento para esse fim. Essas intervenções foram marcadas, na época, pela necessidade de adaptação de imóveis históricos aos usos turísticos - hotéis, pousadas, centros artesanais e culturais -, e pela valorização da "aparência" colonial do edifício, apesar das discussões, já em curso, sobre a importância do Ecletismo no Brasil. Apesar de buscarem atender às normas do chamado "restauro científico", recomendado em documentos internacionais, o histórico desprezo dos arquitetos do Iphan pela arquitetura eclética ainda falou alto e deu o tom das operações de restauração do período, como ilustra a célebre intervenção que transformou a feição eclética e neogótica adquirida pela Sé de Olinda, no "monstrengo colonial" que lá se encontra.

É forçoso reconhecer, contudo, que, antes do PCH, jamais se havia aplicado tantos recursos financeiros na preservação do patrimônio ${ }^{30}$, especialmente em estados do Nordeste. É importante também registrar que, em inúmeros relatórios, buscou-se corrigir desvios e problemas detectados, inclusive por meio do financiamento, após 1976, de planos setoriais, diretores ou de desenvolvimento urbano em várias cidades ${ }^{31}$, numa tentativa, até hoje sem precedentes, de inserção do patrimônio no planejamento urbano local.

\section{Conquistas e desdobramentos do PCH}

A despeito de desvios, problemas e resultados qualitativos globais insuficientes, o PCH empreendeu importantes conquistas e ainda faz jus à sua classificação como um programa de preservação de importância equivalente à do Programa Monumenta, executado entre 2003 e $2010^{32}$. Entre suas principais conquistas, cabe ressaltar a transformação que o programa operou no panorama institucional da preservação do patrimônio no Brasil, mediante a modernização do Iphan e a ampliação do seu território de ação; a criação da maioria dos organismos estaduais de preservação que ainda atuam no país; e mediante, por fim, a construção de um primeiro sistema nacional de preservação do patrimônio no Brasil, alimentado por seu esquema de execução descentralizado.

Com o PCH, o Iphan, que até os anos 1960 atuava, de modo concentrado e sistemático, principalmente em Minas Gerais e no Rio de Janeiro, e que possuía apenas quatro diretorias regionais ${ }^{33}$, passou a atuar em quase todo 0 território nacional por meio da criação de mais quatro novas representações regionais ${ }^{34}$, além das parcerias estabelecidas com os organismos estaduais que foram criados. Por meio de uma coordenação no âmbito federal e de uma execução no plano estadual, o PCH pôs em marcha um sistema de preservação que atuou, ainda que com dificuldades, de modo coordenado e coerente enquanto o programa existiu.

Outra importante conquista se deu no campo da formação profissional e da constituição de um segmento da construção civil voltado para obras de conservação e restauração do patrimônio. No primeiro caso, com o financiamento de quatro cursos de especialização em conservação e restauração de monumentos 
e conjuntos históricos, o PCH formou quadros técnicos para os novos organismos estaduais e empreendeu também a reciclagem e a formação de novos quadros para o Iphan. A despeito de terem ocorrido obras de restauro conceitualmente questionáveis, como a da Sé de Olinda, a qualidade técnica geral das intervenções realizadas no período foi boa, para o que concorreram também os cursos de formação de mão de obra, com a participação de antigos mestres formados no próprio Iphan. Esse trabalho de formação se refletiu na constituição de pequenas e médias empresas voltadas para a restauração do patrimônio, as quais absorveram boa parte da mão de obra formada e foram capazes de realizar, em estados antes desprovidos desse tipo de serviço, trabalhos complexos de restauração. Pode-se afirmar que, graças ao PCH, foram consolidados importantes cursos de especialização nesse campo, como o antigo Curso de Especialização em Conservação e Restauração de Monumentos e Sítios Históricos (CECRE) ${ }^{35}$, da Universidade Federal da Bahia, e o de Conservação e Restauração de Bens Culturais Móveis (CECOR) ${ }^{36}$.

Uma importante consequência, ou desdobramento crítico, da experiência do PCH foi a formulação no âmbito do Iphan, a partir de 1981, de uma nova linha de ação voltada para a preservação do patrimônio urbano, dessa vez no marco do desenvolvimento urbano e da política habitacional. A proposta era conseguir, oferecendo-se como contrapartida os recursos do PCH, a criação, no Banco Nacional de Habitação (BNH), de uma carteira especial de financiamento voltada, principalmente, para a produção habitacional, mas que atuasse também em operações complementares, desenho urbano e apoio técnico. Com base nesses estudos e com a aquiescência do BNH, realizou-se uma operação-piloto em Olinda, Pernambuco, que, apesar de pouco estudada, constitui uma das mais bemsucedidas experiências de preservação fora do binômio "patrimônio e turismo" 37. Essa operação funcionou como estopim para a proposição do Programa de Recuperação e Revitalização de Núcleos Históricos (PRRNH), em 198538, que, infelizmente, não chegou a ser implementado.

Outras heranças não foram, contudo, tão positivas. $\bigcirc$ progressivo esvaziamento dos recursos do PCH, a partir de 1983, e o final dos repasses financeiros aos organismos estaduais parceiros tiveram como impacto a desestruturação do sistema nacional de preservação que havia sido montado pelo programa. Concorreram para essa desestruturação, além da falta de recursos, dois outros aspectos importantes. $\bigcirc$ primeiro relaciona-se à exigência estabelecida pelo programa de criação de legislações de proteção no plano estadual, sem que tenha havido uma reflexão específica sobre seu papel na consolidação de um sistema nacional que, além de projetos, coordenasse também a ação legal das esferas governamentais. Além disso, não foram estudados modelos alternativos, mantendose como único paradigma legislativo o Decreto-lei $n^{\circ} 25 / 1937$. Com isso, os estados participantes do PCH elaboraram leis de tombamento idênticas ou semelhantes à norma federal, o que, após o fim dos repasses financeiros articuladores, favoreceu não somente a instituição de patrimônios federais e
35. Hoje mestrado profissional.

36. Atualmente um curso regular de graduação no âmbito da Escola de Belas Artes da Universidade Federal de Minas Gerais.

37. Ver Marcia Sant'Anna (2014 p. 274-284).

38. O programa foi criado a partir da Exposição de Motivos $\mathrm{n}^{\circ}$ 38/85, de $28 / 11 / 1985$, aprovada pelo Presidente da República e assinada pelos Ministros da Cultura e do Desenvolvimento Urbano e Meio Ambiente. Ver Marcia Sant'Anna (2014, p. 277). 
39. Ver a esse respeito a recomendação relativa à salvaguarda dos conjuntos históricos e sua função na vida contemporânea, aprovada pela Conferência Geral da Unesco realizada em Nairóbi, em 1976. estaduais distintos, mas, principalmente, de linhas de atuação isoladas e descoordenadas. Ou seja, com o fim do dinheiro do PCH, ao invés da permanência de um sistema de preservação articulado pela via legal (inclusive com o estabelecimento de competências diferenciadas e complementares), o que sobrou foi um sistema federal, composto pelo Iphan central e suas representações regionais, e diversos "sistemas" estaduais sem capilaridade, descoordenados entre si, sem diálogo e com ações, muitas vezes, superpostas. Com a entrada de vários municípios na seara da preservação do patrimônio urbano a partir dos anos 1980, esse problema se expandiu, forçando a configuração do que efetivamente temos agora, ou seja, três sistemas ou vias de atuação igualmente descoordenadas, isoladas e superpostas.

O segundo aspecto que também concorreu para a desestruturação do sistema nacional formado pelo PCH foi, a partir da instituição de legislações de tombamento estaduais e municipais, a sedimentação da ideia de que o patrimônio cultural do Brasil pode ser dividido e hierarquizado a partir da atribuição de valores que teriam expressões "nacional", "estadual", "municipal" ou "local". Com isso, sedimentou-se, igualmente, uma noção de que existiriam patrimônios mais valiosos do que outros, o que não somente inibe, até hoje, a ação de identificação e reconhecimento patrimonial nos âmbitos estadual e municipal - já que o tombamento federal é visto como mais importante -, como impede uma ação coordenada das esferas de governo, iá que cada uma delas "cuida" do "seu" específico patrimônio.

Mas talvez uma das consequências mais duradouras da experiência do $\mathrm{PCH}$, que, na realidade, provém do contexto internacional do qual o programa foi tributário, tenha sido a consolidação, no Nordeste, de uma noção de preservação do patrimônio necessariamente vinculada à exploração turística. Como visto, no plano internacional, a concepção de que o turismo era uma das principais vias de viabilização econômica da preservação do patrimônio histórico remonta aos anos 1960. Apesar de já conceitualmente criticada pelos países europeus nos anos 197039, essa concepção se manteve muito forte nos países menos desenvolvidos, onde as dificuldades de alavancar formas mais avançadas de desenvolvimento econômico são maiores e onde o aproveitamento turístico do patrimônio cultural e natural surge, por vezes, como a única esperança para cidades, municípios ou, mesmo, regiões economicamente estagnadas e sem perspectivas de desenvolvimento.

No Brasil, o PCH foi o programa de governo que implementou esse discurso. Apesar dos seus parcos resultados qualitativos, em termos da alteração de situações de estagnação econômica e de deterioração progressiva do estoque construído, o binômio "patrimônio e turismo" permaneceu como a principal âncora de sustentabilidade econômica de programas e projetos implementados muito depois. Assim, é possivel afirmar que uma das principais heranças do PCH foi a consolidação, especialmente no Nordeste do Brasil, da ideia de que o desenvolvimento do turismo é a forma mais adequada de aproveitamento econômico de sítios históricos urbanos degradados que, assim, juntamente com produtos da 
cultura popular local, passaram a ser sistemática e inescapavelmente submetidos às lógicas de museificação, espetacularização e sazonalidade inerentes a essa atividade.

\section{Lições do PCH que não foram aprendidas}

A despeito das críticas explicitadas ao longo do desenvolvimento do $\mathrm{PCH}$ relativas à baixa capacidade de revitalização econômica a partir do turismo, a proposta inicial do Programa Monumenta foi exatamente essa ${ }^{40}$. Em recente balanço das realizações deste último programa, Bonduki o define como herdeiro do PCH por essa razão, pela sua estrutura institucional descentralizada, que incluiu os municípios, pelo financiamento federal da utilização econômica do patrimônio e pelo apoio a atividades complementares, como a formação de mão de obra ${ }^{41}$.

Além desse foco inicial na promoção da atividade turística, outros equívocos cometidos na execução do PCH foram repetidos na formulação e na implementação do Monumenta, certamente porque lições deixadas pelo programa anterior não foram consideradas. Uma delas diz respeito a não se prever (no caso do $\mathrm{PCH}$ ), ou a se deixar em segundo plano (no caso do Monumenta), os investimentos no fortalecimento institucional dos parceiros locais ou, em outras palavras, da "ponta" executiva do programa. Com isso, da mesma forma que o $\mathrm{PCH}$, o Monumenta enfrentou grandes dificuldades pela falta de estrutura municipal adequada.

Outra lição não aprendida pelos programas mais novos se relaciona ao baixo investimento no fortalecimento do uso habitacional e em planos voltados para identificação e tratamento dos problemas estruturais e processos urbanos de maior abrangência que afetam os sítios históricos, a fim de se aumentar as chances de sustentabilidade do conjunto de obras e intervenções realizadas. Além disso, a ausência de investimentos na dimensão normativa da preservação do patrimônio urbano -providência necessária para se evitar a descaracterização das áreas sob intervenção, especialmente se sua dinamização econômica for bem-sucedida.

$\mathrm{PCH}$ já havia também demonstrado - e essa questão somente foi abordada no final da execução do Monumenta - que não é possível transformar realidades complexas, como a dos centros históricos de grandes cidades, com intervenções pontuais de restauração e conservação de edifícios históricos, sem a integração de outras áreas de governo ligadas ao transporte, à política habitacional, ao saneamento e à infraestrutura. Os impactos do Monumenta nas grandes cidades foram, de fato, quase nulos em comparação com o que ocorreu nas cidades pequenas e médias. Esse resultado remete ao mesmo problema de pulverização de recursos financeiros que já havia ocorrido no $\mathrm{PCH}$, ao invés de se promover a sua concentração em situações nas quais se pode, efetivamente, fazer a diferença.

Embora a experiência do PCH não tenha sido considerada na formulação do Monumenta, este último programa não foi, contudo, apenas uma repetição de erros do passado, já que desenvolveu e iniciou a implementação de
40. O Programa Monumenta constituiu a política integrada de preservação do patrimônio urbano que sucedeu o PCH e foi fruto de contrato de financiamento firmado com o Banco Interamericano de Desenvolvimento (BID), em 1999, tendo sido oficialmente concluído por volta de 2011.

41. Ver Nabil Bonduki (2010, p 28). 
42. Natividade, em Tocantins; Goiás Velho, em Goiás; Cachoeira e Lençóis, na Bahia; e em Penedo, Alagoas. Ver Nabil Bonduki (2010 p. 273). uma das ações mais interessantes de preservação do patrimônio urbano dentre as que foram executadas no país. Seu antecedente pode ser identificado na já comentada experiência de promoção do uso habitacional, realizada em Olinda, como um dos desdobramentos do PCH. Trata-se do financiamento da conservação e da restauração de imóveis privados existentes em sítios históricos por meio de empréstimos sem juros, cujo pagamento se reverte para um Fundo Municipal de Preservação que tem a missão de reinvestir no próprio sítio. Embora tenha sido desenvolvida plenamente em poucas cidades ${ }^{42}$, essa ação provou ter grande potencial de sustentação, do ponto de vista social e econômico, da preservação de sítios urbanos históricos, especialmente em cidades pequenas e médias.

O atual PAC-CH, lançado em 2009, como uma proposta inovadora e baseada na revisão dos fracassos e acertos dos programas anteriores, infelizmente não vem se revelando inovador e vem repetindo, com intensidade, alguns equívocos do passado. Apresentado como uma política descentralizada e integrada com outras áreas de governo, estabeleceu-se, inicialmente, que as intervenções desse programa estariam sempre articuladas a planos de ação, elaborados localmente e de modo participativo, destinados a ir além do âmbito dos sítios históricos sempre que problemas estruturais apontassem essa necessidade. Outro componente importante seria o reforço e a ampliação da experiência de financiamento de imóveis privados realizada pelo Monumenta, vista então como uma das principais âncoras de um processo de preservação aliado ao desenvolvimento urbano. Contudo, o PAC-CH tem sido executado de modo diverso e tem repetido - e até ampliado-vários dos equívocos mais importantes que foram cometidos no período do $\mathrm{PCH}$.

Para começar, ao cortar o financiamento da conservação de imóveis privados e transformar os planos de ação num mero elenco de obras desconectadas, - PAC-CH não apresenta qualquer alternativa consistente de dinamização econômica e de uso socialmente significativo do patrimônio urbano, para além da velha, já desgastada e pouco produtiva fórmula do "patrimônio, turismo e lazer". Os já conhecidos e insuficientes resultados dessa apropriação continuarão, assim, impactando negativamente a configuração dos sítios históricos, e impedindo com sua lógica um aproveitamento mais diversificado, economicamente significativo e socialmente inclusivo desses setores.

Até o momento, portanto, a história das políticas de preservação no Brasil, representadas pelo PCH, pelo Monumenta e pelo PAC-CH, mostra que não conseguimos avançar de modo crescente e consistente na direção de uma conservação sustentada do nosso vasto patrimônio urbano e de sua ampla apropriação, também do ponto de vista simbólico, pela sociedade. Apesar de suas conquistas e avanços, o PCH e os novos programas nos mostram a recorrência de problemas que entravam a consolidação no Brasil de uma política de preservação permanente e consistente.

Um primeiro problema recorrente diz respeito à ampliação da abrangência territorial dos programas, sem que seus resultados tenham tempo de 
se produzir e consolidar numa escala menor, o que ocasiona dispersão e pulverização de recursos e, por fim, sua progressiva transformação em rubricas orçamentárias que alimentam obras nem sempre prioritárias ou fundamentais. Esse resultado é também decorrência da histórica falta de planos ou políticas locais de preservação que articulem os investimentos e alimentem impactos mais positivos e abrangentes. A ausência ou a colocação num plano secundário das ações de fortalecimento das estruturas executivas locais é outra importante recorrência negativa, assim como a dificuldade de percepção dos limites do uso turístico do patrimônio, além da eterna permanência, no plano discursivo ou no âmbito da execução insuficiente, das iniciativas que buscam articular patrimônio, planejamento urbano e políitica habitacional. Por fim, a falta de ação coordenada e complementar das esferas públicas para além dos eventuais programas de governo - o que, como já demonstrou o $\mathrm{PCH}$, não se efetivará meramente pela via do repasse de recursos e sim pelo estabelecimento de instrumentos legais, de planejamento e de gestão compartilhados e por meio de instrumentos de financiamento da ação privada adequados e permanentes.

Inúmeros países já desenvolveram esses instrumentos e políticas, a exemplo da França, da Inglaterra, da ltália, dentre outros. Por aqui, estamos ainda presos ao voluntarismo dos grandes programas, às suas eventuais conquistas e, principalmente, às suas falhas recorrentes. A esperança depositada no PAC-CH já se esvaiu completamente e não há no horizonte nada que a possa abrigar. 


\section{REFERÊNCIAS}

\section{LIVROS, ARTIGOS E TESES}

BONDUKI, Nabil. Intervenções urbanas na recuperação de centros históricos. Brasília: Iphan; Programa Monumenta, 2010.

BRASIL. Cartas patrimoniais. $3^{\text {a }}$ edição, versão aumentada. Rio de Janeiro: Iphan, 2004.

CORRÊA, Sandra Rafaela Magalhães. O Programa de Cidades Históricas (PCH): por uma política integrada de preservação do patrimônio cultural. 2012. Dissertação (Mestrado em Arquitetura e Urbanismo) - Universidade de Brasília, Brasília, 2012.

CYSNE, Rubens Penha. A economia brasileira no período militar. In: SOARES, Glaucio Ary Dillon; D'ARAUJO, Maria Celina (org.). 21 anos de regime militar: balanços e perspectivas. Rio de janeiro: Fundação Getúlio Vargas, 1994, p. 232-270.

OLIVEN, Ruben George. A relação Estado e cultura no Brasil: cortes ou continuidade? In: Sérgio Miceli (org.). Estado e cultura no Brasil. São Paulo: DIFEL, 1984, p. 50-51.

PARENT, Michel. Protection et mise en valeur du patrimoine culturel brésilien dans le cadre du développement touristique et économique. Paris: UNESCO, mar. 1968.

SANT'ANNA, Marcia. A cidade-atração: a norma de preservação de centros urbanos no Brasil dos anos 90. 2004. Tese (Doutorado em Arquitetura e Urbanismo) -Universidade Federal da Bahia, Salvador, 2004.

Da cidade-monumento à cidade-documento: a norma de preservação de áreas urbanas no Brasil 1937-1990. Salvador: Oiti Editora, 2014.

TEIXEIRA, Ricardo dos Santos. Uma conjuntura de aparências: a construção de um sistema municipal de planejamento urbano em Ouro Preto. 2014. Tese (Doutorado em Arquitetura e Urbanismo) - Universidade Federal de Minas Gerais, Belo Horizonte, 2014.

Artigo apresentado em 20/01/2016. Aprovado em 08/06/2016. 